\title{
A molecular dynamics study of structure and dynamics of surfactant molecules in SDS spherical micelle
}

\author{
N.Yoshii ${ }^{1}$, S.Okazaki ${ }^{2 *}$ \\ 1 Department of Pharmaceutical Sciences, Himeji Dokkyo University, Himeji 670-8524, Japan \\ 2 Institute for Molecular Science, Myodaiji, Okazaki 444-8585, Japan
}

Received November 5, 2007

\begin{abstract}
An analysis of structure and dynamics of surfactant molecules in SDS micelle is presented based on molecular dynamics calculations. Two-dimentional surface correlation function for the hydrophilic sulfur atoms as well as the bond analysis between the hydrophobic alkyl chains shows that the surfactant molecules are packed sparsely in the micelle such that they form a soccer ball-like structure characterized by the coordination number of three. The hydrophobic bond between the surfactant molecules is produced and annihilated repeatedly in a time scale of about $100 \mathrm{ps}$ but disappears by their diffusion in a time scale of about $1 \mathrm{~ns}$.
\end{abstract}

Key words: molecular dynamics, micelle, surfactant

PACS: $71.15 . P d, 82.70 . U v$

\section{Introduction}

Physical chemistry of micelles has been attracting constant interest of researchers in its long history because of an abundance of polymorphism in water, i.e. a variety of structure formations of the surfactant molecules in water [1-4]. Recently, several molecular dynamics (MD) calculations have been done for spherical micelles formed in water, which leads the researcher's interest to the structure and dynamics at a molecular level [5-12].

In a number of our previous studies [13-16], structural stability of the spherical sodium dodecyl sulfate (SDS) micelle has been analyzed based on the free energy using MD calculations. Firstly, size distribution of the micelle in water was quantitatively investigated by calculating the free energy of micelle formation as a function of the micelle size $N$ using thermodynamic integration method [13]. The distribution showed a sharp peak at $N=57$ with the full width at half height of about 4 . Then, the molecular origin of this stability, in other words, the instability of the micelles that are smaller or larger than the stable one was investigated in detail in terms of hydrophobic interaction, cavity formation in the micelle core, repulsion between sulfate ions on the surface, and bridging of the sulfate ions by sodium ions [14-16].

Here, in the present study, we focus our attention on the structure and dynamics of the surfactant molecules in the micelle. In particular, coordination of a surfactant molecule by the surrounding surfactant molecules as well as the dissociation dynamics of the bond between them were investigated from the trajectories of our molecular dynamics calculations.

\section{Calculation}

Molecular dynamics calculations have been performed for SDS spherical micelles in water. Three micelle sizes, $N=41,61$, and 81 , were tested, among which the second one is the most stable and mostly found in water. One spherical micelle and 8,488 water molecules are contained in a cubic cell in the periodic boundary condition. The standard Nosè-Hoover chain as well as the Andersen isotropic cell fluctuation method was adopted in order to control the system at $T=300 \mathrm{~K}$ and

*E-mail: okazaki@ims.ac.jp 


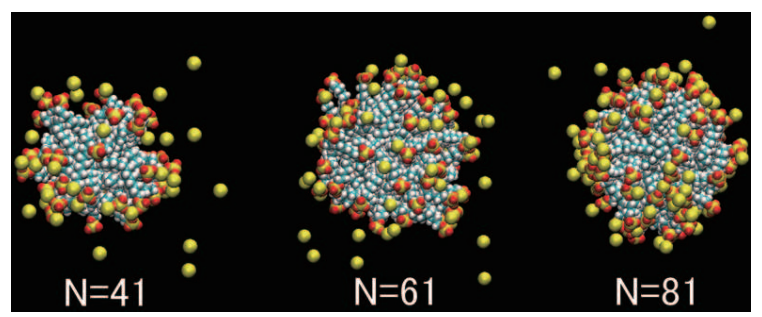

Figure 1. Snapshots of the simulated SDS spherical micelles formed in water. In the figure, water molecules are not drawn just for clarification.

$P=1 \mathrm{~atm}$. The equations of motion were solved using the method by Martyna et al. $[17,18]$. The CHARMM $[19,20]$ and TIP4P [21] potential parameters were used to model the surfactant and water molecules, respectively. The particle-mesh Ewald method was applied to the evaluation of the long-ranged coulombic interaction. The SHAKE/ROLL and RATTLE/ROLL algorithms were also used in order to impose constraints on the bond length with respect to the hydrogen atoms [17]. Time step $\Delta t$ was $1 \mathrm{fs}$. After the equilibration runs for $1 \mathrm{~ns}$, the trajectories were sampled from the production runs longer than 1 ns.

\section{Results and discussion}

A snapshot of the micelles sampled from the trajectories is presented in figure 1 for three sizes tested in the present study. The micelles of size $N=61$ and 81 are all quite spherical, though the smaller one $N=41$ is slightly distorted.

In order to investigate the structure of the spherical micelles, two-dimensional surface correlation function $g(R \theta)$ was defined by

$$
g(R \theta)=\frac{2}{N(N-1)} \frac{2}{\sin \theta \Delta \theta} d\left(\theta-\frac{\Delta \theta}{2}, \theta+\frac{\Delta \theta}{2}\right),
$$

where $N$ is the micelle size or the number of surfactant molecules in the micelle, $R$ is the averaged distance from the center of mass of the micelle and the sulfur atom of the surfactant molecule, i.e. the averaged radius of the spherical micelle, and $\theta$ is the angle between two vectors $\mathbf{R}_{\mathbf{i}}$ and $\mathbf{R}_{\mathbf{j}}$ from the center of mass of the micelle to the sulfur atoms of the i-th and j-th surfactant molecules, respectively. The angle $\theta$ is calculated by

$$
\theta=\arccos \left(\frac{\mathbf{R}_{\mathbf{i}} \cdot \mathbf{R}_{\mathbf{j}}}{\left|\mathbf{R}_{\mathbf{i}}\right|\left|\mathbf{R}_{\mathbf{j}}\right|}\right) .
$$

$d\left(\theta-\frac{\Delta \theta}{2}, \theta+\frac{\Delta \theta}{2}\right)$ is the number of pairs of the surfactant molecules whose $\theta$ is found between $\theta-\frac{\Delta \theta}{2}$ and $\theta+\frac{\Delta \theta}{2}$. Thus, $R \theta$ correspond to the distance walking on the surface from one sulfur atom to the other projected on the surface. The $g(R \theta)$ may be regarded as two-dimensional surface radial distribution function on the surface of the averaged sphere.

The calculated $g(R \theta)$ is presented in figure 2 for the micelle of size $N=41,61$, and 81 . The figure clearly shows an oscillatory behavior of the function for the large micelles, $N=61$ and 81 , implying that the structure is a liquid-like one. On the other hand, noticeable correlation is not found for the small micelle, $N=41$, except for the first peak. The function is not oscillatory but monotonically approaches unity at long $R \theta$. The arrangement of the surfactant molecules on the surface of the small micelle is likely to be a gas-like one, showing unsystematic fluctuation of the surrounding surfactant molecules.

Integrating the surface correlation function to $9 \AA$, the first minimum of $g(R \theta)$ for the micelle of size $N=61$, the number of the sulfur atoms $n_{\mathrm{ss}}$ found in the first coordination shell was calculated and listed in table 1 . Although the coordination number increases slightly with the increasing micelle size, it turns out to be around 3 for all micelles. This is quite small compared to 6 , the 


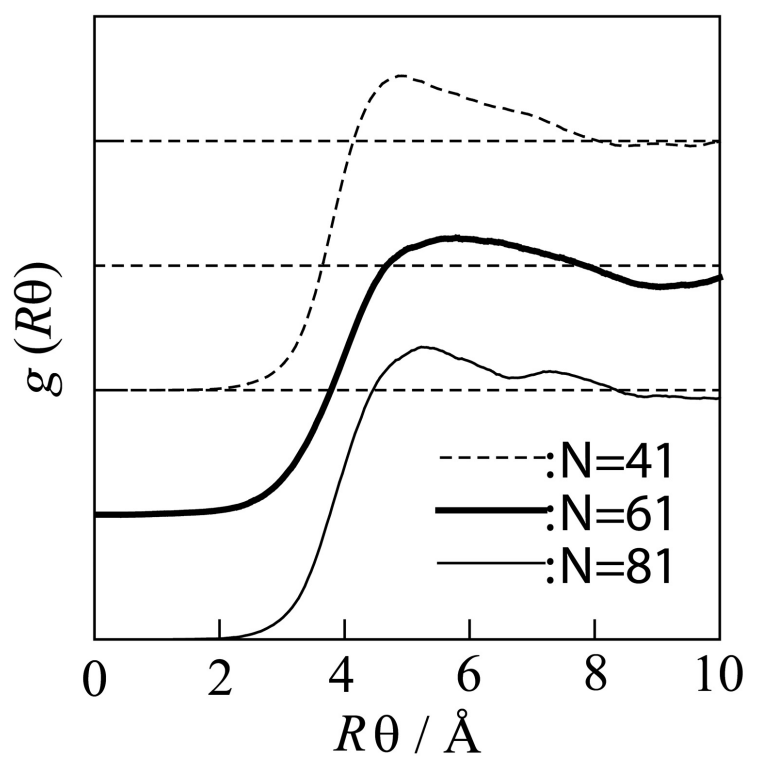

Figure 2. Two-dimensional correlation function for the hydrophilic sulfur atoms of the SDS surfactant molecules projected on the surface of the spherical micelle of radius $R$. For details, see the text.

Table 1. Calculated coordination number $n_{\mathrm{ss}}$ of the hydrophilic sulfur atom on the surface of the SDS micelle, number of the bonds $n_{\mathrm{cnt}}$ between hydrophobic alkyl chains in the micelle core, and relaxation time $\tau$ of the bond density correlation function between the hydrophobic alkyl chains in the core.

\begin{tabular}{ccccc}
\hline$N$ & $n_{\mathrm{ss}}$ & $n_{\mathrm{cnt}}\left(S \geqslant 60 \AA^{2}\right)$ & $n_{\mathrm{cnt}}\left(10 \AA^{2} \leqslant S \leqslant 60 \AA^{2}\right)$ & $\tau / \mathrm{ns}$ \\
\hline 41 & 2.8 & 2.8 & 5.5 & 0.8 \\
61 & 3.1 & 3.0 & 5.6 & 1.1 \\
81 & 3.7 & 3.1 & 5.9 & 1.2 \\
\hline
\end{tabular}

one for the two-dimensional closest packing. Thus, the hydrophilic groups form a sparse surface structure. The coordination number of 3.0 for the micelle of size $N \approx 60$ reminds us of the soccer ball structure found for the fullerene $\mathrm{C}_{60}$, although the bond found in this system is essentially different from the $s p^{2}$ chemical bond. In fact, $n_{\mathrm{ss}}$ found for the micelle of $N=81$ is 3.7, showing a distorted but still similar to that found for $\mathrm{C}_{80}$ for which the bonding number is absolutely 3 . In the present micelle system, the structure may continuously change to a denser one as the size becomes greater.

In order to analyze the structure of the micelles more in detail, we defined a bond between the long hydrophobic groups of the dodecyl sulfate ions inside the micelle core. Here, we define the bond between two hydrophobic chains by their contact area $S$ of Voronoi polyhedrons relevant to the hydrophobic groups.

Firstly, Voronoi analysis was performed for the carbon atoms of $\mathrm{CH}_{2}$ and $\mathrm{CH}_{3}$ groups of a SDS molecule. Then, the area of the polyhedrons relevant to the hydrophobic groups which is in contact with the hydrophobic groups of the other SDS molecules was obtained. The calculated distribution of the contact area $f(S)$ is presented in figure 3. From the figure, it is clear that the distribution may be classified into three. The first one is a major distribution found for $S$ less than $10 \AA^{2}$. The second is a peak found around $S=30 \AA^{2}$ and the last one is a shoulder around $S=100 \AA^{2}$. These are commonly found for three micelles. Clearly, the first one may be considered to come from the non-bonded molecule, the third one represents the entirely bonded pair, and the second is the partially bonded one. Now, we are able to separately count the number of surrounding surfactant 


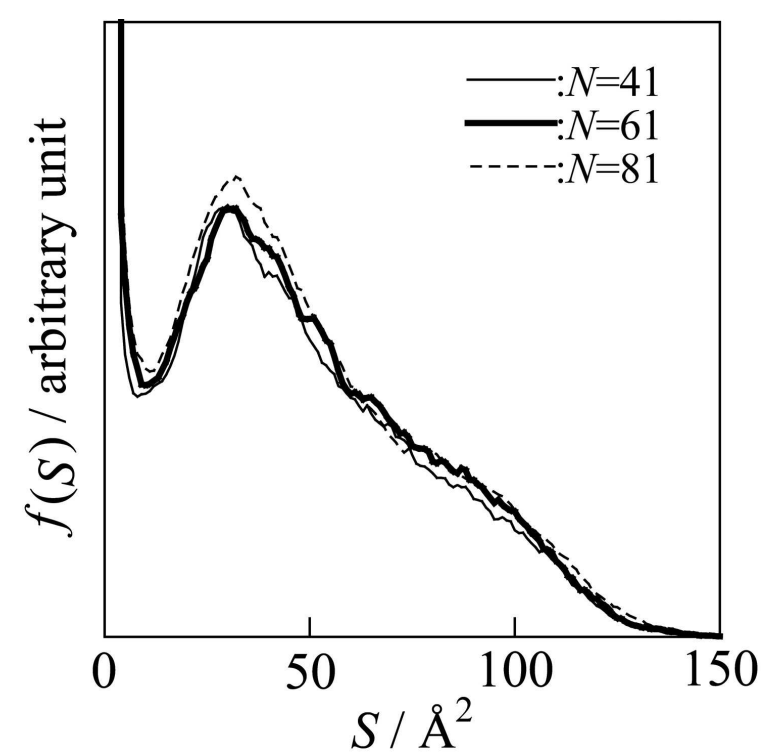

Figure 3. Distribution of the contact area of the Voronoi polyhedrons between the hydrophobic alkyl chains of the SDS surfactant molecules in the micelle. For details, see the text.

molecules with $S \leqslant 10 \AA^{2}, 10 \AA^{2}<S \leqslant 60 \AA^{2}$, and $S>60 \AA^{2}$. The averaged bond number $n_{\text {cnt }}$ of the molecules which have large contact $S>60 \AA^{2}$ with a central molecule is $2.8,3.0$, and 3.1 for the micelle of $N=41,61$, and 81, respectively, as shown in table 1 . These are in good agreement with the findings for the number of the hydrophilic sulfate groups in the first coordination shell on the surface. The number of molecules with medium contact, $10 \AA^{2}<S \leqslant 60 \AA^{2}$, is 5.5, 5.6, and 5.9 for $N=41,61$, and 81, respectively. The remaining number of molecules may be related to the ones with small contact area, $S \leqslant 10 \AA^{2}$. All these results clearly show that the skeleton structure of the surfactant molecules in the micelle is similar to those found for the fullerene where the number of directly bonded carbon atoms is 3 and the second ones is 6 .

In the micelle, the surfactant molecules are bound to each other by hydrophobic interaction. Since the interaction is not so strong, the molecules associate and dissociate repeatedly inside a micelle, i.e. a migration takes place. This is a big difference from the rigid fullerenes. Now, it is interesting to investigate this association and dissociation dynamics from a microscopic viewpoint.

In order to examine the above recombination dynamics of the surfactant molecules as well as their diffusion in the micelle, we applied an analysis used previously for the clusters formed in supercritical fluid, where the decrease of the bond density was monitored [22]. A bond matrix between the surfactant molecules may be described following the definition by the contact area above

$$
n_{i j}= \begin{cases}1, & \text { if } S \geqslant 10 \AA^{2} \text { between molecules i and } \mathrm{j}, \\ 0, & \text { otherwise. }\end{cases}
$$

Calculating this matrix element, we may define the bond density correlation function $B(t)$ as

$$
B(t)=\frac{\sum_{i>j}\left\langle\left\{n_{i j}(t)-\left\langle n_{i j}\right\rangle\right\}\left\{n_{i j}(0)-\left\langle n_{i j}\right\rangle\right\}\right\rangle}{\sum_{i>j}\left\langle\left\{n_{i j}(0)-\left\langle n_{i j}\right\rangle\right\}^{2}\right\rangle},
$$

which describes how the density of the bond found at $t=0$ decreases as a function of time. The function is normalized such that it is unity at $t=0$ and zero at $t=\infty$.

The calculated function is shown in figure 4 for three micelles. In the figure, a two-step relaxation is found commonly among the three. The fast one at small $t$ is caused by the translational libration of the surfactant molecules and the slow one after it comes from the diffusion of the molecules. The relaxation time for the former is roughly of the order of $100 \mathrm{ps}$. The total relaxation time $\tau$ was evaluated by integrating the function from $t=0$ to $\infty$ after the exponential extrapolation 


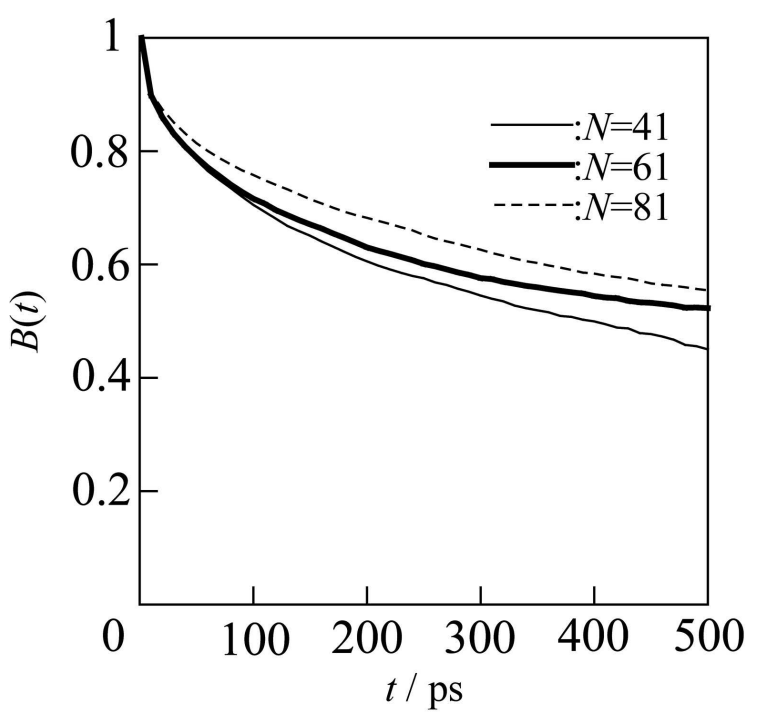

Figure 4. Bond density correlation function between the hydrophobic alkyl chains of the SDS surfactant molecules in the micelle defined by the contact area of the Voronoi polyhedrons. For details, see the text.

at large $t$. The calculated relaxation time is listed in table 1 . The value ranging from 0.8 ns to $1.2 \mathrm{~ns}$ is quite long compared to the fast relaxation of about $100 \mathrm{ps}$ found at small $t$. This means that the bond with a neighboring molecule is broken by its diffusion during which production and annihilation of the bond between them is repeated about 10 times.

\section{Conclusion}

We presented a molecular dynamics analysis for the structure and dynamics of the SDS micelles formed by the surfactant molecules in water. The calculated two-dimensional surface distribution function for the hydrophilic sulfur atoms shows a liquid-like structure for the large micelles while a gas-like one is found for the small micelle. In particular, the micelle of size $N=61$ shows the coordination number of $n_{\mathrm{ss}}=3.1$ of the sulfur atoms around a central sulfur atom. This implies that a soccer ball-like structure is formed.

Bond analysis between the hydrophobic alkyl chains in the micelle core also shows the number of bonds $n_{\mathrm{cnt}}=3.0$ with the neighboring molecules and $n_{\mathrm{cnt}}=5.6$ with the second neighboring molecule. This is in good agreement with the findings in the analysis of the above surface correlation function.

The bond is produced and annihilated quite frequently compared with the slow diffusion of the molecule. It disappears by the diffusion, repeating the production and annihilation of the bond by the translational libration about ten times.

\section{Acknowledgements}

This work was supported by the Next Generation Supercomputing Project, Nanoscience Program, MEXT, Japan. The work was also supported by Grant-in-Aid for Scientific Research (Nos. 17105001 and 18066020) from Japan Society for the promotion of Science. The authors thank Okazaki Research Center for Computational Science, National Institutes of Natural Sciences for the use of supercomputers. 


\title{
References
}

1. Everett D.H. Basic Principles of Colloid Science. The Royal Society of Chemistry, London, 1988.

2. Hamley I.W. Introduction to Soft Matter Polymers. Colloids, Amphiphiles and Liquid Crystals, John Wiley \& Sons, West Sussex, 2000.

3. Israelachvili J.N. Intermolecular and Surface Forces. 2nd edition, Academic Press, London, 1992.

4. Encyclopedia of Surface and Colloid Science, Vol. 4, edited by A. T. Hubbard, Marcel Dekker, New York, 2002.

5. Bruce C.D., Senapati S., Berkowitz M.L., Perera L., Forbes M.D.E., J. Phys. Chem. B, 2002, 106, 10902.

6. Bruce C.D., Berkowitz M.L., Perera L., Forbes M.D.E., J. Phys. Chem. B, 2002, 106, 3788.

7. Rakitin A.R., Pack G.R., J. Phys. Chem. B, 2004, 108, 2712.

8. Tieleman D.P., D. van der Spoel, Berendsen H.J.C., J. Phys. Chem. B, 2000, 104, 6380.

9. Sterpone F., Briganti G., Pierleoni C., Langmuir, 2001, 17, 5103.

10. Sterpone F., Pierleoni C., Briganti G., Marchi M., Langmuir, 2004, 20, 4311.

11. Pal S., Balasubramanian S., Bagchi B., J. Phys. Chem. B, 2003, 107, 5194.

12. Matubayasi N., Liang K.K., Nakahara M., J. Chem. Phys., 2006, 124, 154908.

13. Yoshii N., Iwahashi K., Okazaki S., J. Chem. Phys., 2006, 124, 184901.

14. Yoshii N., Okazaki S., Chem. Phys. Lett., 2006, 425, 58.

15. Yoshii N., Okazaki S., Chem. Phys. Lett., 2006, 426, 66.

16. Yoshii N., Okazaki S., J. Chem. Phys., 2007, 126, 096101.

17. Martyna G.J., Tuckerman M.E., Tobias D.J., Klein M.L., Mol. Phys., 1996,87, 1117.

18. Martyna G.J., Tobias D.J., Klein M.L., J. Chem. Phys., 1994, 101, 4177.

19. MacKerrell A.D., Jr., Bashfold D., Bellott M. et al., J. Phys. Chem., 1998, 102, 3586.

20. MacKerrell A.D., Jr., Feig M., Brooks III C.L., 2004, 25, 1400.

21. Jorgensen W.L., Chandrasekhar J., Madura J.D., Impey R.M., Klein M.L., J. Chem. Phys., 1983, 79, 926.

22. Yoshii N., Okazaki S., J. Chem. Phys., 1997, 107, 2020.

\section{Молекулярно-динамічне вивчення структури і динаміки сурфактних молекул в сферичній міцелі додецилсульфату натрію}

\author{
Н.Йоші ${ }^{1}$, С.Оказакі ${ }^{2}$ \\ 1 Факультет фармацевтичних наук, Гімеї Докіо університет, м. Гімеї, Японія \\ 2 Інститут молекулярних наук, м. Оказакі
}

Отримано 5 листопада 2007 р.

\begin{abstract}
На основі молекулярно-динамічних розрахунків представлено аналіз структури і динаміки сурфактних молекул в міцелі додецилсульфату натрію. Двомірна поверхня кореляційної функції гідрофільних атомів сірки та аналіз зв'язків гідрофобними вуглецевими ланцюжками показує, що сурфактні молекули є впаковані хаотично в міцелі так, що вони утворюють структуру, подібну до футбольного м'яча, що характеризується координаційним числом рівним трьом. Гідрофобний зв'язок між молекулами сурфактанту виникає та анігелює неодноразово в числовій школі порядку 100 ps, але зникає завдяки дифузії у часовій шкалі порядку $1 \mathrm{~ns}$.
\end{abstract}

Ключові слова: молекулярна динаміка, міцела, сурфактант

PACS: $71.15 . P d, 82.70 . U_{v}$ 